December 2017

\title{
JMASM 50: A Web-based Shiny Application for Conducting a Two Dependent Samples Maximum Test (R)
}

Saverpierre Maggio

Wayne State University, spmaggio@uwindsor.ca

Gokul Bhandari

University of Windsor, Ontario

Shlomo S. Sawilowsky

Wayne State University

Follow this and additional works at: http://digitalcommons.wayne.edu/jmasm

Part of the Applied Statistics Commons, Social and Behavioral Sciences Commons, and the Statistical Theory Commons

\section{Recommended Citation}

Maggio, S., Bhandar, G., \& Sawilowsky, S. S. (2017). JMASM 50: A Web-based Shiny Application for Conducting a Two Dependent Samples Maximum Test (R). Journal of Modern Applied Statistical Methods, 16(2), 576-579. doi: 10.22237/jmasm/1509496260

This Algorithms and Code is brought to you for free and open access by the Open Access Journals at DigitalCommons@WayneState. It has been accepted for inclusion in Journal of Modern Applied Statistical Methods by an authorized editor of DigitalCommons@WayneState. 


\section{JMASM 50: A Web-based Shiny Application for Conducting a Two Dependent Samples Maximum Test (R)}

\author{
Saverpierre Maggio \\ Wayne State University \\ Detroit, MI
}

\author{
Gokul Bhandari \\ University of Windsor \\ Windsor, ONT, CAN
}

\author{
Shlomo S. Sawilowsky \\ Wayne State University \\ Detroit, MI
}

A web-based Shiny application written in $\mathrm{R}$ statistical language was developed and deployed online to calculate a new two dependent samples maximum test as presented in Maggio and Sawilowsky (2014b). The maximum test allows researchers to conduct both the dependent samples $t$-test and Wilcoxon signed-ranks tests on same data without raising concerns associated with Type I error inflation and choice of statistical tests (Maggio and Sawilowsky, 2014a). The maximum test in R statistical language provides a friendly user interface.

Keywords: Maximum test, Wilcoxon signed-ranks test, Type I error inflation, $\mathrm{R}$ programming, Shiny application, Dependent samples t-test

\section{Introduction}

The dependent samples $t$-test is used if data are known or expect to be normally distributed. If not, and it is assumed that the treatment alternative is a shift in means then the Wilcoxon Signed-Ranks (WSR) test is to be used (Blair \& Higgins, 1985; Bridge \& Sawilowsky, 1999; Gerke \& Randles, 2010; Wiederman $\&$ Alexandrowicz, 2011). Researchers that conduct both tests on the same data unavoidably increase the experiment-wise Type I error rate.

A new maximum test excel calculator was introduced by Maggio and Sawilowsky (2014b). It is based on the maximum of the dependent samples t-test and the Wilcoxon Signed-Ranks (WSR) test. The critical value was previously obtained from the joint sampling distribution for the two tests, thereby eliminating concern for Type I error inflation (Maggio \& Sawilowsky, 2014a) when

Dr. Maggio is an Adjunct Faculty member in the Department of Evaluation and Research, College of Education. Email him at: spmaggio@uwindsor.ca. Dr. Bhandari is Associate Professor of Information Systems at Odette School of Business. Dr. Sawilowsky is Professor in the Department of Evaluation and Research, College of Education, and the Editor of this Journal. Email him at shlomo@wayne.edu. 


\section{MAGGIO ET AL.}

conducting both tests. This new test also eliminates choice of one test over another thus allowing multiple tests on same data either serially or in parallel.

\section{Purpose}

The purpose of this article is to provide a web-based Shiny application written in $\mathrm{R}$ that calculates the two dependent samples maximum test as in Maggio and Sawilowsky (2014a). This application allows for column names (headers) and separators such as commas, semicolons, or tabs. The locations of the data columns for dependent samples can also be indicated by providing an appropriate column number for Series 1 and Series 2 as shown in Figure 1.

\section{Methodology}

The application is available online at https://datawise.shinyapps.io/maxtest/. A screenshot of the application in R located in Figures 1 and 2.

\section{Input}

The process of obtaining the maximum test $p$-values, critical values and a determination of whether or not to "reject" or "fail to reject" a null hypothesis is as follows:

1. As shown in Figure 1, upload a comma separated values (CSV) file by clicking on the "Choose File" button.

2. Select the significant levels such as 0.05 or 0.01

3. Select one-tail test or two-tail test.

\section{Conclusion}

The application reports in the second tab "Data" displays the uploaded data for visual confirmation. In the third tab " $t$-test" reports the output for the $t$-test (statistic, $p$-value, and degrees of freedom). The fourth tab reports the output of the "Wilcoxon Signed Rank Test" (statistic and $p$-value). The fifth tab "Maximum Test Output" reports the maximum of the two tests, critical values of the dependent samples $t$-test and WSR test, maximum test critical value, effective 


\section{A SHINY APPLICATION IN R}

significance level of the tests, and the decision whether to reject the null or fail to reject the null.

The maximum test can be used in lieu of choice between the dependent samples $t$-test and the WSR where "both the classical parametric and nonparametric tests can be safely conducted on the same data, with the maximum of the two refereed to the new table of critical values that are designed to maintain the Type I error rate to nominal $\alpha$ while guaranteeing the maximum power of the two tests" (Maggio \& Sawilowsky, 2014b, p.4).

Critical values for a two tailed test and an example to follow was provided for in Maggio and Sawilowsky (2014a). An easy to use calculator in excel was provided in Maggio and Sawilowsky (2014b).

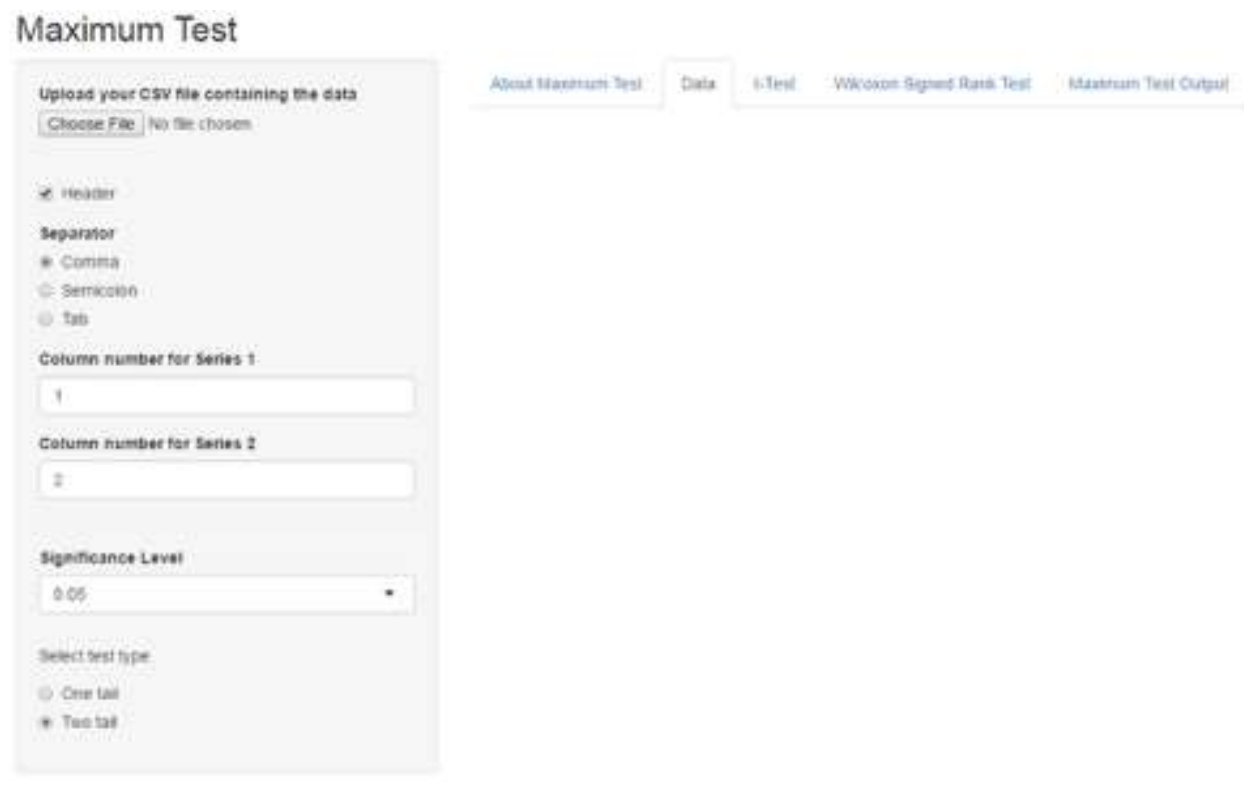

Figure 1. Interface of the web-based application 


\section{MAGGIO ET AL.}

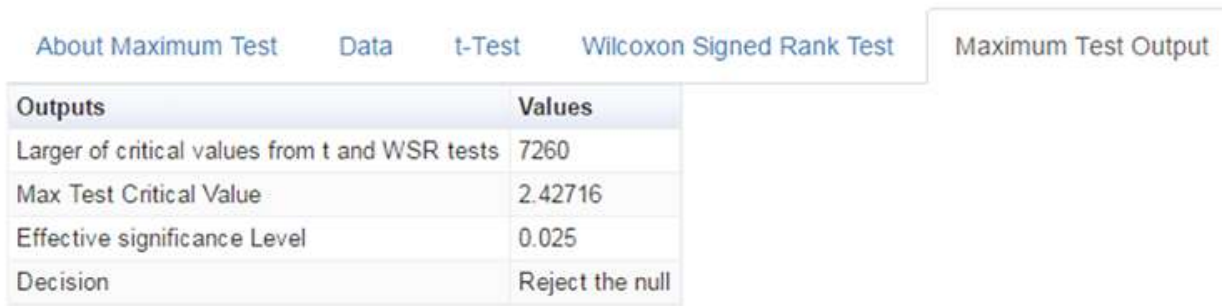

Figure 2. Example of an out from the Maximum test

\section{References}

Blair, R. C. \& Higgins, J. J. (1985). Comparison of the power of the paired samples t test to that of Wilcoxon's sign-ranks test under various population shapes. Psychological Bulletin, 97(1), 119-128. doi: 10.1037/0033-2909.97.1.119

Bridge, P. K. \& Sawilowsky, S. (1999). Increasing physician's awareness of the impact of statistical tests on research outcomes: Investigating the comparative power of the Wilcoxon rank-sum test and independent samples $t$-test to violations from normality. Journal of Clinical Epidemiology, 52(3), 229-235. doi: 10.1016/s0895-4356(98)00168-1

Gerke, T. A. \& Randles, H. (2010). A method for resolving ties in asymptotic relative efficiency. Statistics and Probability Letters, 80(13), 10651069. doi: 10.1016/j.spl.2010.02.021

Maggio, S. \& Sawilowsky, S. (2014a). A new maximum test via the dependent samples t-test and the Wilcoxon sign rank test. Applied Mathematics, 5(10), 110-114. doi: 10.4236/am.2014.51013.

Maggio, S. \& Sawilowsky, S. (2014b). JMASM 33: A Two Dependent Samples Maximum Test Calculator: Excel. Journal of Modern Applied Statistical Methods, 13(1), 514-518. doi: 10.22237/jmasm/1398918660

Wiederman, W. T., \& Alexandrowicz, R. W. (2011). A modified normal scores test for paired data. Methodology: European Journal of Research Methods for the Behavioral and Social Sciences, 7(1), 25-38. doi: 10.1027/16142241/a000020 